\title{
Penetration Control of Surface Sizing Starch Using Cationic PAM and Its Effect on the Bending Stiffness of Paper
}

\author{
Man Seok Seo, ${ }^{\text {a }}$ Hye Jung Youn, ${ }^{\text {b,c }}$ and Hak Lae Lee ${ }^{\text {b,c,* }}$ \\ Surface sizing is employed to increase the wetting resistance against \\ liquids and to improve strength and surface properties of paper. Starch \\ solution is the most widely used for surface sizing, and its effect is highly \\ dependent upon how deep the starch solution penetrates into the paper \\ structure. Better tensile strength can be obtained when starch penetrates \\ deep into the thickness direction of paper. However, holdout of starch \\ solution is beneficial for improving the stiffness and air or liquid resistance. \\ This study was focused on the use of cationic polyacrylamide (PAM) as a \\ surface sizing additive to control the penetration of starch solutions into \\ paper, thus improving bending stiffness of paper. The effects of the ionic \\ property, viscosity, and charge density of PAM on starch penetration and \\ bending stiffness of surface sized papers were investigated. The \\ penetration of starch solution was investigated with confocal laser \\ scanning microscopy. The enthalpy changes accompanying the mixing of \\ cationic PAMs with oxidized starch was determined using an isothermal \\ titration calorimeter to see the molecular level interaction between PAM \\ and starch in mixing. The addition of cationic PAM to oxidized starch \\ solution made starch molecules stay on the paper surface rather than \\ penetrating into the paper structure.
}

Keywords: Surface sizing, Bending stiffness; Starch; Cationic PAM; Penetration

Contact information: a: KT\&G, 30, Gonjeong-ro, Yuseong-gu, Daejeon, 34128, Korea; b: Program in Environmental Materials Sciences, Department of Forest Sciences, College of Agriculture and Life Sciences, and Research Institute for Agriculture and Life Sciences, Seoul National University, 1 Gwanakro, Gwanak-gu, Seoul, 08826 South Korea; c: State Key Laboratory of Biobased Material and Green Papermaking, Qilu University of Technology (Shandong Academy of Sciences), Jinan, 250353, the People's Republic of China; *Corresponding author: lhakl@snu.ac.kr

\section{INTRODUCTION}

Increasing the filler content in printing paper is one of the most effective approaches to achieve cost savings in papermaking because it allows the substitution of expensive fibers with low cost fillers (Hubbe and Gill 2016). Increasing filler content also provides opportunities to improve many paper properties such as opacity, brightness, smoothness and printability. However, conventional ways of increasing filler loading often result in decreases of mechanical properties, which limits the filler level in paper products (Gill and Hagemeyer 1992; Hubbe and Gill 2016). Stiffness is the most seriously affected property with the increase of filler content in paper. To alleviate the problem of strength reduction associated with the increase of filler content, papermakers have developed various methods including lumen loading, shape modification and agglomeration of fillers, coflocculation of fillers and fiber fines, preflocculation of fillers, and coating of filler particles with dry strength polymers, etc. (Fairchild 1985; Tommey et al. 1997; Kettuner et al. 2000; 
Porubská et al. 2002; Chauhan et al. 2011; Kumar et al. 2011; Im et al. 2015). These methods decrease the loss of many strength properties of paper compared with the conventional filler loading system (Bown 1998; Lee et al. 2002; Lee and Lee 2006; Hubbe and Gill 2016). It is unavoidable, however, to lose strength properties of papers with the increase of filler contents even though above-mentioned various approaches are employed. This indicates that new methods or technologies should be found to solve the problem of strength reduction associated with the increase of filler content of paper.

Surface sizing compensates for the detrimental effects of fillers on paper strength. In surface sizing, starch is applied to paper surface, where it cements fibers to the body of paper and deposits a more or less continuous film on the paper surface. Many surface sizing agents including starch, polyvinyl alcohol copolymers of styrene and acrylate (SAE), water-soluble polyurethane (PUD), copolymers of styrene and acrylate (SAA), copolymers of styrene and maleic anhydride (SMA) have been developed and used (Hodgson 1994; Samyn et al. 2010). Among them, oxidized starch is the most widely used for surface sizing because it is available at low cost and shows excellent resistance against retrogradation and good fiber bonding capability (Kearney 2005). Oxidized starch solution, however, tends to penetrate deeply into the paper structure, leaving less starch film on the surface. Thus, it has a marginal effect on improving the bending stiffness (Kajanto 1998; Lee et al. 2002). Layer structure is the most effective way to obtain high bending stiffness, and this can be made by surface sizing when the size does not penetrate into the sheet (Kolger et al. 1992). To reduce the penetration of starch solution into paper, it is necessary to increase the solids content of sizing solution or to promote interaction between starch and fiber. Lipponen et al. (2004) have shown that by increasing the surface size solids content, the penetration of the starch into the sheet can be decreased, which improves surface strength and bending stiffness. Because the fiber is negatively charged, cationic starch or additives increase the interaction of the sizing agents with fiber. The application of cationic additives to increase the holdout of coating colors has been studied by Kogler et al. (1992). They showed that cationic coating color improved coating holdout, fiber coverage, and printability. Lee et al. (2002) showed that the use of cationic starch instead of oxidized starch in surface sizing improved bending stiffness, optical properties, and printability. Anionic trash load during broke recycling was also reduced. Jun and Lee (2008) have shown that surface sizing with cationic starch improves the coverage and optical properties of coated papers. The overall change of an anionic surface sizing system to a cationic one, however, increases the cost of paper production due to the higher price of cationic starches.

Recently, graft copolymerization of starch by different monomers has been used to modify the surface sizing starch (Kim et al. 2017; Rajabi Abhari et al. 2017). In starch graft-copolymer, functional groups are attached to the main chain of starch along with their backbone monomers. This modification of starch improves the starch properties because functional groups and various monomers with desirable characteristics can be attached to starch molecules. Acrylic acid, acrylamide, methacrylic acid, and other acrylic/vinyl monomers are used for grafting onto starch. Rajabi Abhari et al. (2017) showed that addition of dextrin poly(acrylic acid) copolymer has beneficial effects on starch holdout. Because of its lower penetration into linerboard, higher compressive and bending strengths of sized paper sheet were obtained. This improvement in mechanical properties made it possible to reduce the pickup weight of the surface sizing agent around $23 \%$ while keeping the mechanical properties at a same level. Ni et al. (2017) showed that surface sizing with enzymatically degraded starch and 3-aminopropyl trimethoxysilane (APMS) improved the physical properties of paper because APMS forms covalent linkages with cellulose. The 
approaches of using starch graft-copolymers or specialty chemicals, however, have a serious economic disadvantage.

It is needed, therefore, to develop a method to improve the holdout of surface sizing agent on paper surface without using cationic or graft starch system that requires complete substitution of low cost oxidized starches with expensive cationic starch or starch copolymers. In other words, a method to improve the surface sizing efficiency with the use of cationic additives is needed. In this study, various cationic polyacrylamides (PAMs) were tested as surface sizing additives for improving starch holdout and stiffness. Penetration phenomena of the surface sizing agents into paper and the enthalpy changes accompanying the mixing of cationic PAMs with oxidized starch were investigated to evaluate the hypothesis that the bending stiffness of paper can be improved by the addition of cationic PAM additives to surface sizing solution.

\section{EXPERIMENTAL}

\section{Materials}

Oxidized corn starch (Sunsize, Samyang Genex, Daejeon, Korea) in powder form and diverse PAMs (Woojin Industry, Ltd. Kunsan, Korea) with different charge densities, molecular weights, and ionic properties were utilized for surface sizing. PAMs used in this study were liquid solutions, and their solids contents were $20.0 \pm 1.0 \%$. Low shear viscosity and charge density of the polymers and starch are summarized in Table 1. Low shear viscosity in Table 1 was measured using a Brookfield viscometer (DV-IP, Brookfield Engineering Laboratories, Inc., Middleborough, MA, USA) at $20{ }^{\circ} \mathrm{C}$. A no. 1 spindle of the Brookfield viscometer was placed in the $0.5 \%$ solution of starch or polymer. Spindle rotation speed of $60 \mathrm{rpm}$ was employed for the measurement. Charge density was determined using a streaming current detector (Mütec PCD, BTG, Germany) with $0.01 \mathrm{~N}$ of poly-diallyldimethylammonium chloride (poly-DADMAC) or sodium polyethylene sulfonate (PES-Na) as a titrating solution. Molecular weights of PAMs and SA were provided by the manufacturer. Styrene acrylic acid copolymer (SA, Woojin Industry, Ltd. Kunsan, Korea) was used as an additive for surface sizing.

To examine the effect of molecular weight of PAM, two cationic PAMs with high and low Brookfield viscosities were used. They were HV.C-PAM (high viscosity cationic PAM) and LV.C-PAM (low viscosity cationic PAM). These two PAMs showed similar charge densities, while their viscosity values were quite different. Cationic and anionic PAMs were also used to evaluate the influence of charge types. And two cationic PAMs with high charge density (HC.C-PAM) and low charge density (LC.C-PAM) were used to investigate the effect of cationic charge density of PAM as a surface sizing additive. The difference of their viscosities was around $12 \%$, while the difference in their charge density was $290 \%$. LV.C-PAM was the same polymer as HC.C-PAM.

Acridine orange (Sigma Aldrich, St. Louis, MO, USA) was used as a fluorescent dye to stain the starch and PAM (Lee et al. 2002). Sodium hydroxide solution (1 N) (Sigma Aldrich, St. Louis, USA) was used to control the $\mathrm{pH}$ of starch solution. Handsheets made with hardwood bleached kraft pulp (Moorim P\&P, Ulsan, Korea) were used for surface sizing experiment. 
Table 1. Properties of Polymers Used for Surface Sizing

\begin{tabular}{|c|c|c|c|}
\hline Polymers & $\begin{array}{c}\text { Charge } \\
\text { Density } \\
(\mathrm{meq} / \mathrm{g})\end{array}$ & $\begin{array}{c}\text { Viscosity }(\mathrm{cPs}) \\
\left(0.5 \%, 20^{\circ} \mathrm{C}\right)\end{array}$ & $\begin{array}{c}\text { Molecular } \\
\text { Weight } \\
\text { (Dalton) }\end{array}$ \\
\hline Oxidized starch (OS) & -0.16 & 7.0 & \\
\hline Styrene acrylic acid copolymer (SA) & -3.23 & 5.0 & 100,000 \\
\hline High viscosity cationic PAM (HV.C-PAM) & 1.42 & 7.6 & 500,000 \\
\hline Low viscosity cationic PAM (LV.C-PAM) & 1.19 & 2.5 & 200,000 \\
\hline High charge density PAM (HC.C-PAM) & 1.19 & 2.5 & 200,000 \\
\hline Low charge density PAM (LC.C-PAM) & 0.41 & 2.8 & 200,000 \\
\hline Anionic PAM (HV.A-PAM) & -2.34 & 7.0 & 500,000 \\
\hline
\end{tabular}

\section{Methods}

\section{Forming handsheets}

Handsheets with basis weights of $100 \pm 2.0 \mathrm{~g} / \mathrm{m}^{2}$ were prepared according to TAPPI T205 sp-02 (2002). Hardwood BKP was beaten to $450 \mathrm{~mL}$ CSF in a laboratory Hollander beater. Sheets were formed on a square sheet former and pressed under the pressure of 345 $\mathrm{kPa}$ for $5 \mathrm{~min}$. Handsheets were cylinder-dried at $120{ }^{\circ} \mathrm{C}$ and conditioned at $50 \%$ relative humidity (RH) and $23 \pm 2{ }^{\circ} \mathrm{C}$ for over $48 \mathrm{~h}$.

\section{Preparation of surface sizing agents and surface sizing}

Oxidized corn starch was cooked for $30 \mathrm{~min}$ at $95{ }^{\circ} \mathrm{C}$ at $10 \%$ consistency. The $\mathrm{pH}$ of starch solution was controlled to 8.5 using sodium hydroxide solution (1 N). PAM solution was added to the cooked starch solution with mechanical stirring, and then styrene acrylic acid copolymer was added and mixed thoroughly, when specified. The solids content and temperature of the final starch solution were kept constant at $10 \%$ and $50{ }^{\circ} \mathrm{C}$, respectively. The amounts of PAM and SA were kept constant at 5 parts per hundred (pph) of the starch weight in all experiments.

During surface sizing, the temperature of the starch solution was kept constant at $50{ }^{\circ} \mathrm{C}$ using a constant temperature heating system. Starch solution was applied to paper using an automatic rod coater (PI-1210 Film coater, Tester Sangyo Co. Ltd., Saitama, Japan). A no. 10 wire-wound rod and coating speed of $53.0 \pm 2.0 \mathrm{~mm} / \mathrm{sec}$ were employed to control the starch pickup at $4.5 \pm 0.45 \mathrm{~g} / \mathrm{m}^{2}$. Only one side of the handsheet was surface sized. After surface sizing, it was hot air dried at $105{ }^{\circ} \mathrm{C}$ and cylinder dried at $120{ }^{\circ} \mathrm{C}$. Surface sized papers were conditioned at $50 \% \mathrm{RH}$ and $23 \pm 2{ }^{\circ} \mathrm{C}$ for over $48 \mathrm{~h}$. After conditioning, the handsheet weight, the pickup weight, and the thickness were measured according to TAPPI standard (T $411 \mathrm{om}-97,1997)$. Bending resistance of the samples was measured using a bending resistance tester (ISO 5628, 2019). All measurements were reported with error bars of $95 \%$ confidence intervals.

\section{Evaluation of interaction between starch and PAM}

Thermal titrations were carried out using an ultra-sensitive isothermal titration calorimeter (MicroCal VP-ITC, Malvern Panalytical, Malvern, UK). Before the titration, all samples were degassed using a MicroCal ThermoVac for 5 min. The differential power between the sample cell and the reference cell was $5 \mu \mathrm{cals}^{-1}$. Titration data were processed by MicroCal Origin version 5.0, and background titration heat was subtracted. In the isothermal titration calorimetry experiments, $0.5 \%$ cationic PAM solution was gradually added drop-by-drop ( $5 \mu \mathrm{L}$ per drop) into $1.6 \mathrm{~mL}$ of $0.5 \%$ oxidized solution at $50{ }^{\circ} \mathrm{C}$, and 
the resulting heat effect of each injection was measured. The time interval between drops was $180 \mathrm{~s}$ and the temperature remained constant at $50{ }^{\circ} \mathrm{C}$. The results are expressed as heat flow into the calorimeter. Thus, a positive heat reading indicates an endothermic reaction and a negative reading means an exothermic reaction.

\section{Analysis of starch penetration into paper}

Ten $\mathrm{mL}$ of $0.05 \%$ acridine orange solution was added to $300 \mathrm{~mL}$ of $10 \%$ starch solution at $50{ }^{\circ} \mathrm{C}$ and stirred (Weber et al. 2004). Acridine orange absorbs the visible light with wavelengths of $480 \mathrm{~nm}$ and emits fluorescence at $530 \mathrm{~nm}$. Surface sizing with starch solutions containing acridine orange was carried out with an automatic rod coater (PI-1210 Film coater, Tester Sangyo Co. Ltd., Saitama, Japan). Starch pickup was controlled at 2.5 $\pm 0.25 \mathrm{~g} / \mathrm{m}^{2}, 4.0 \pm 0.40 \mathrm{~g} / \mathrm{m}^{2}$, and $6.0 \pm 0.60 \mathrm{~g} / \mathrm{m}^{2}$ by controlling the speed of the laboratory rod coater at $60.0 \pm 2.0 \mathrm{~mm} / \mathrm{sec}, 55.0 \pm 2.0 \mathrm{~mm} / \mathrm{sec}$ and $48.0 \pm 2.0 \mathrm{~mm} / \mathrm{sec}$, respectively. The thicknesses of the papers after surface sizing at three different speeds were $5.1 \pm 0.38$ $\mu \mathrm{m}, 7.2 \pm 0.63 \mu \mathrm{m}$, and $10.2 \pm 0.96 \mu \mathrm{m}$, respectively. Then the surface sized handsheet was air dried at $105^{\circ} \mathrm{C}$, and cylinder dried at $120^{\circ} \mathrm{C}$. Conditioning of surface-sized papers was carried out in a standard conditioning room for over $48 \mathrm{~h}$, and the pickup weight and thickness of paper after surface sizing were evaluated according to TAPPI standard (T 411 om-97, 1997). Cross sections of the paper were observed using a confocal laser scanning microscope (CLSM). Ar laser (power: $9.5 \mathrm{~mW}$ ) was used as a light source for CLSM analysis. A dichroic beam splitter, which separates the fluorescent wavelengths from the excitation wavelength of the Ar laser, was used. The pinhole size was set at the optimum value for each objective lens.

\section{RESULTS AND DISCUSSION}

\section{Effects of PAM on the Physical Properties of Handsheet}

To examine the effect of PAM addition on handsheet properties, starch solutions containing different types of PAM with or without SA were prepared and applied on the handsheet. The effect of PAM to starch solution on pickup weight is shown in Fig. 1.

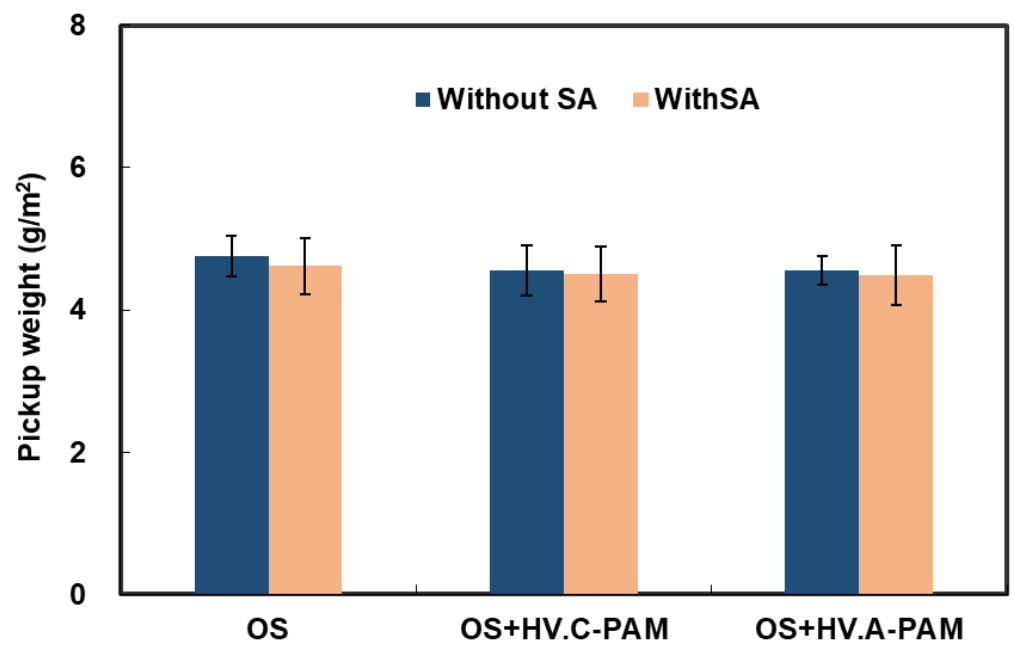

Fig. 1. Effect of addition of high viscosity cationic and anionic PAMs on the pickup weight of surface sizing agents 
The effect of ionic properties of PAM on pickup weight was also evaluated. The Brookfield viscosities of cationic and anionic PAMs in Fig. 1 were $7.6 \mathrm{cPs}$ and $7.0 \mathrm{cPs}$, respectively. Average pickup weights were approximately $4.5 \pm 0.45 \mathrm{~g} / \mathrm{m}^{2}$ irrespective of PAM types. The addition of SA into starch solution showed no significant change in pickup weight. Thus, these two additives did not cause significant variations in the pickup weight, which allowed us direct comparison of bending stiffness and penetration of surface sizing solutions into the thickness direction of paper.

The effect of the addition of cationic and anionic PAMs in starch solutions with or without SA on the bending stiffness of paper is shown in Table 2. The bending stiffness of base paper and surface sized paper with oxidized starch only was $0.77 \mathrm{mN} \cdot \mathrm{m}$ and 0.81 $\mathrm{mN} \cdot \mathrm{m}$, respectively. Surface sizing with oxidized starch improved bending stiffness by $5.1 \%$. The addition of SA to starch solution did not improve bending stiffness, indicating that SA did not change the penetration of starch solution and stiffness of the dried film.

The use of high viscosity cationic PAM as a surface sizing additive improved the bending stiffness by $7.5 \%$. In contrast, there was not much improvement in the bending stiffness when anionic PAM was used as a surface sizing additive. This result suggested that electrostatic interactions between two oppositely charged polymers enhanced the holdout of surface sizing solution and thereby increased the bending stiffness of paper. Table 2 also shows the effects of viscosity of cationic PAMs on bending stiffness. When low viscosity cationic PAM was used, the bending stiffness increased by $11.0 \%$, while high viscosity PAM improved the bending stiffness only by $7.5 \%$. This result suggests that low viscosity PAM was more effective in improving the starch holdout. This was probably because the number of polymer molecules of PAM was far greater when low molecular weight PAM was used, which provided more uniform interaction between two sizing materials.

Kajanto (1998) have shown that the use of short dwell time application leaves the size at the surface, which increases the bending stiffness more than $50 \%$ with the same amount of size. Theoretically, higher elastic modulus on the surfaces than in the middle of sheet would give higher bending stiffness. For instance, if each surface layer is $5 \%$ of the paper thickness, then doubling their elastic modulus raises bending stiffness by $27 \%$ (Kajanto 1998). This suggested that the higher bending stiffness for the low viscosity CPAM was obtained because it gave either better holdout of sizing solution or better film forming opportunity for greater elastic modulus of the surface layer, or both. The effect of electrostatic interaction between sizing solution and paper substrate has been investigated by Lee et al. (2002), and they have shown that an increase in holdout of starch solution can be achieved using cationic starch. Lipponen et al. (2004) have shown that the holdout of the starch solution improves surface strength and bending stiffness of paper.

The effects of charge density of cationic PAM on bending stiffness can be seen by comparing the data of LV.CPAM and LC.CPAM. It is clear that the use of high charge density PAM resulted in a greater increase of bending stiffness than low charge density PAM, probably because it increased starch holdout on paper surface. The combined use of cationic PAM and SA further increased the bending stiffness, but the use of SA along with anionic PAM showed a negative effect on bending stiffness. This result shows that electrostatic interaction between starch and surface sizing additives is important for the improvement of bending stiffness (Gaudreault et al. 2005). 
Table 2. Effect of Oxidized Starch (OS), Cationic and Anionic PAMs and SA on Bending Stiffness of Paper

\begin{tabular}{|c|c|c|}
\hline $\begin{array}{c}\text { Surface Sizing Agent } \\
\text { Composition }\end{array}$ & $\begin{array}{c}\text { Bending Stiffness } \\
(\mathrm{mNm})\end{array}$ & $\begin{array}{c}\text { Bending Stiffness, mNm } \\
\text { (SA was added after PAM) }\end{array}$ \\
\hline Base paper & $0.770 \pm 0.026$ & \\
\hline OS & $0.809 \pm 0.023(5.1 \%)$ & $0.810 \pm 0.018(5.2 \%)$ \\
\hline OS + HV. CPAM & $0.828 \pm 0.017(7.5 \%)$ & $0.844 \pm 0.019(9.6 \%)$ \\
\hline OS + HV. APAM & $0.816 \pm 0.015(6.0 \%)$ & $0.804 \pm 0.036(4.4 \%)$ \\
\hline OS + LV. CPAM & $0.855 \pm 0.030(11.0 \%)$ & $0.890 \pm 0.026(15.6 \%)$ \\
\hline OS + LC. CPAM & $0.838 \pm 0.042(8.8 \%)$ & $0.870 \pm 0.041(13.0 \%)$ \\
\hline
\end{tabular}

*OS: oxidized starch, HV; high viscosity, LV; low viscosity, CPAM; cationic polyacryl amide, SA; styrene acrylic acid copolymer

The effect of the addition order of cationic PAM and SA on bending stiffness was examined. When SA was added before HV.CPAM, bending stiffness decreased by 0.01 $\mathrm{mNm}$ to $0.834 \pm 0.025 \mathrm{mNm}$. In the case of LV.CPAM, reduction of $0.02 \mathrm{mNm}$ in bending stiffness occurred to give $0.870 \pm 0.024 \mathrm{mNm}$. The addition of cationic PAM after SA gave lower bending stiffness than prior addition of cationic PAM to SA. This result suggests that the interaction between starch and cationic PAM is more effective than the interaction between SA and cationic PAM for improving the bending stiffness. The addition of SA before high viscosity cationic PAM, however, gave higher bending stiffness than when only cationic PAM was used as additive without SA.

The degree of improvement in bending stiffness depended on the PAM viscosity. As shown in Table 1, the charge densities of high and low viscosity PAMs were $1.42 \mathrm{meq} / \mathrm{g}$ and $1.19 \mathrm{meq} / \mathrm{g}$, respectively, and their viscosities were $7.6 \mathrm{cPs}$ and $2.5 \mathrm{cPs}$, respectively. The addition of high viscosity cationic PAM increased the viscosity compared to starch only case. In contrast, the addition of low viscosity cationic PAM decreased the viscosity by 1.3 or $1.4 \mathrm{cPs}$ (Table 3 ). This result showed that greater bending stiffness increase with low viscosity cationic PAM was not derived from the viscosity increase. The charge density of starch solution containing high and low viscosity C-PAMs were $-0.15 \mathrm{meq} / \mathrm{g}$ and $-0.13 \mathrm{meq} / \mathrm{g}$, respectively. Because the charge density of low viscosity C-PAM (1.19 $\mathrm{meq} / \mathrm{g}$ ) was lower than that of high viscosity C-PAM (1.42 meq/g), low viscosity C-PAM showed greater electrostatic interaction with oxidized starch than high viscosity C-PAM. The viscosity data showed that the intermolecular interaction between oxidized starch and the low viscosity C-PAM was less than that of the high viscosity C-PAM. The charge densities of starch solutions decreased as SA was added because the charge density of SA was $-3.23 \mathrm{meq} / \mathrm{g}$.

Sequential addition of $5 \mathrm{pph}$ of a cationic PAM and 5 pph of SA with constant stirring did not give any sticky materials or deposits. The viscosity of starch solution did not change much when cationic PAM and SA were added in order, probably because the cationic PAM interacts uniformly with starch to generate microflocs. However, the addition of SA to starch solution followed by the addition of a high viscosity PAM caused a dramatic increase in viscosity. This indicated that extensive reaction between SA and cationic PAM occurred, which gave large polymer flocs. This showed that the sequential addition of cationic PAM and SA should be made to avoid the formation of polymer complex. 
Table 3. Charge Density and Brookfield Viscosity of Sizing Solutions Containing High and Low Viscosity Cationic PAM and Styrene Acrylic Acid Copolymer (SA)

\begin{tabular}{|c|c|c|c|c|c|}
\hline & $\begin{array}{c}\text { Charge } \\
\text { density } \\
(\mathrm{meq} / \mathrm{g})\end{array}$ & $\begin{array}{c}\text { Viscosity } \\
(\mathrm{cPs})\end{array}$ & $\begin{array}{c}\text { Charge } \\
\text { density } \\
(\mathrm{meq} / \mathrm{g})\end{array}$ & $\begin{array}{c}\text { Viscosity } \\
(\mathrm{cPs})\end{array}$ \\
\hline OS & -0.16 & 11.5 & OS + SA & -0.36 & 11.8 \\
\hline $\begin{array}{c}\text { OS + } \\
\text { HV. C-PAM }\end{array}$ & -0.15 & 12.7 & $\begin{array}{c}\text { OS + } \\
\text { HV. C-PAM+SA }\end{array}$ & -0.29 & 12.0 \\
\hline $\begin{array}{c}\text { OS + } \\
\text { LV. C-PAM }\end{array}$ & -0.13 & 10.1 & $\begin{array}{c}\text { OS + } \\
\text { LV. C-PAM+SA }\end{array}$ & -0.30 & 10.5 \\
\hline
\end{tabular}

The penetration of starch affects the optical properties of paper (Lee et al. 2002; Hubbe and Gill 2016). To investigate the effect of cationic PAM on optical properties of paper, the brightness and opacity were determined after surface sizing using cationic PAMs and SA as additives (Fig. 2). The brightness of unsized base paper was $83.1 \%$. Surface sizing with oxidized starch decreased brightness because the oxidized starch is less white in color and its brightness was lower than hardwood bleach pulp. More importantly, penetration of starch solutions into the pore caused a reduction of light scattering, which is crucial for brightness. It has been shown that brightness reduction with surface sizing increases as the amount of starch pickup increases (Lee et al. 2002). The paper surface sized with cationic PAM showed relatively high brightness. The addition of low viscosity cationic PAM gave the highest brightness, which was further increased with SA addition. It is interesting to see that the brightness change accompanied with the use of PAM in surface sizing was very similar to the change of bending stiffness. This suggested that the holdout of surface sizing materials on paper surface is important for bending stiffness and optical properties of paper.

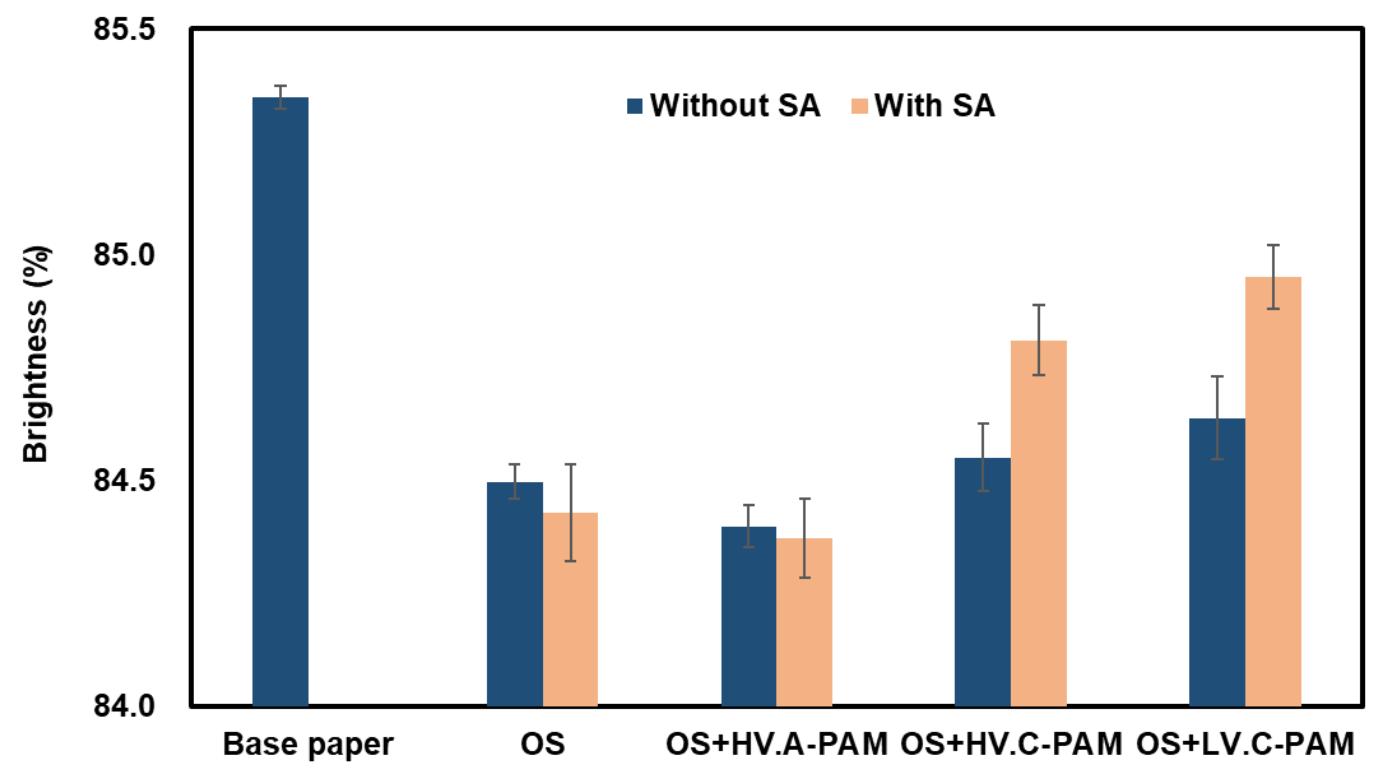

Fig. 2. Effect of addition of anionic and cationic PAMs on pickup weight of surface sizing agents

The enthalpy changes when low and high viscosity cationic PAMs were mixed with oxidized starch were investigated using ITC and shown in Fig. 3, which showed the level of thermodynamic interaction between cationic PAM and oxidized starch (Lipponen et al. 2004; Nyström et al. 2004; Seo et al. 2012). Enthalpy change between low viscosity PAM 
and oxidized starch was higher than that between high viscosity PAM and starch. This indicates that low molecular weight PAM interacts with oxidized starch more actively compared to high viscosity PAM, which probably provide much stronger interaction between two components. Less interaction between the high viscosity PAM and starch led to less improvement of bending stiffness.

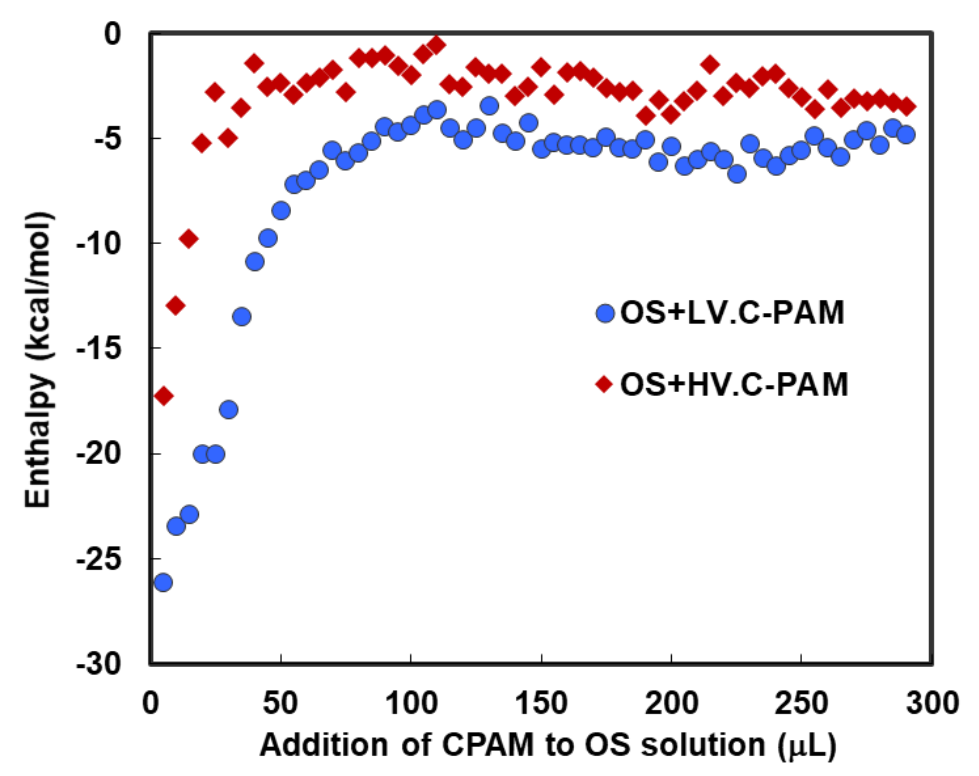

Fig. 3. Enthalpy change between high and low viscosity PAM and oxidized starch

\section{Z-Directional Distribution of Starch}

Results of bending stiffness and optical properties suggested that addition of cationic PAM increased the surface holdout of surface sizing starches. To obtain more direct evidence on the holdout of surface sizing solutions associated with the use of cationic PAMs, CLSM images of the cross section of surface sized papers were obtained. This method is very useful to investigate the $\mathrm{z}$-directional distribution of starch in the paper (Lee et al. 2002).

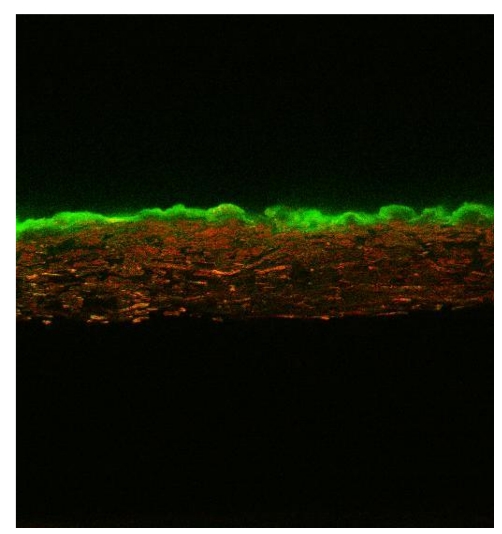

$2.5 \pm 0.25 \mathrm{~g} / \mathrm{m}^{2}$

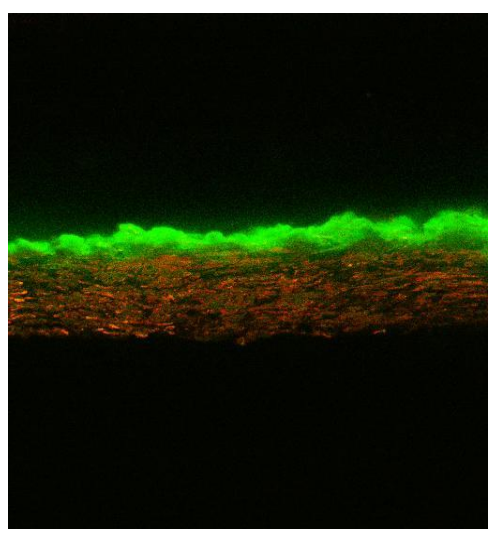

$4.0 \pm 0.40 \mathrm{~g} / \mathrm{m}^{2}$

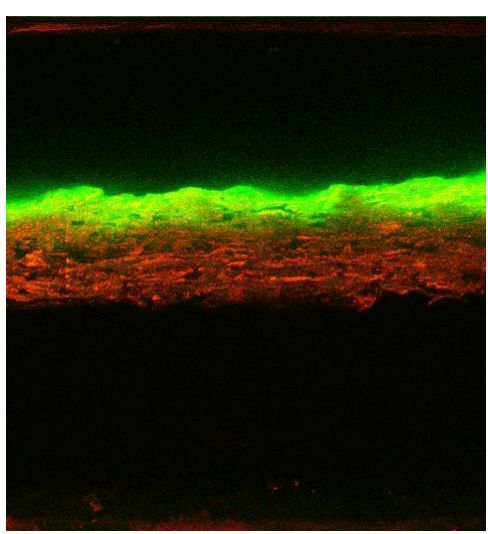

$6.0 \pm 0.60 \mathrm{~g} / \mathrm{m}^{2}$

Fig. 4. CLSM image of paper surface sized with starch solution containing acridine orange. Green color shows the presence of acridine orange which was applied with starch solution 
Acridine orange (Sigma Aldrich, St. Louis, MO, USA) was used as a fluorescent dye to stain the starch and PAM. Acridine orange that possesses anionic charge density $(-2.30$ $\mathrm{meq} / \mathrm{g}$ ) was added to starch slurry during the cooking process to stain the starch. The acridine orange stained starch can be detected because it emits fluorescence at $530 \mathrm{~nm}$.

CLSM images of the surface sized handsheets with different pickup weights are shown in Fig. 4. Basis weight and thickness of the handsheet before surface sizing were $100 \pm 2.0 \mathrm{~g} / \mathrm{m}^{2}$, and $148 \pm 1.69 \mu \mathrm{m}$, respectively, and the density of paper was $675 \mathrm{~kg} / \mathrm{m}^{3}$. The images in Fig. 4 clearly show that fluorescence intensity increased with an increase of pickup weight. The depth of fluorescence also increased with starch pickup weight.

Because the green color in CLSM images indicates the presence of acridine orange contained in starch solution, the distribution of starch solution in z-direction can be evaluated by the intensity of the green color. The fluorescence intensity profile is shown in Fig. 5. The amount of the surface sizing agent remained on paper surface was high, but it decreased as the distance from the paper surface increased. This agrees with the results reported by Lee et al. (2002). They pointed out that the starch content was quite high in the vicinity of the surface, and decreased abruptly inside of the paper. The CLSM image showed that surface sizing starch did not penetrate all the way to the back side. The penetration depth of starch solution has been investigated by Lipponen et al. (2004). Starch penetration into paper depends on the viscosity and temperature of the solution, pressure applied to the solution, time of absorption, and interaction between the solution and paper substrate. Of course, the pickup weight is another important factor of the penetration depth.

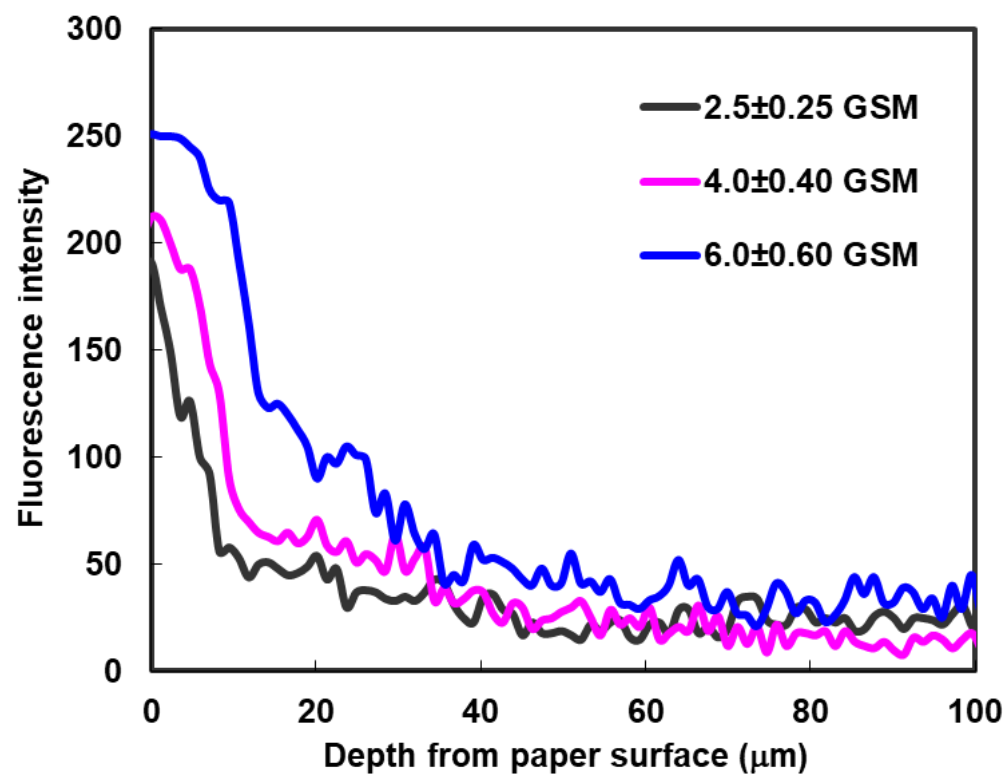

Fig. 5. Fluorescence profile of the surface sized papers with pickup weights of $2.5 \pm 0.25 \mathrm{~g} / \mathrm{m}^{2}$, $4.0 \pm 0.40 \mathrm{~g} / \mathrm{m}^{2}$ and $6.0 \pm 0.60 \mathrm{~g} / \mathrm{m}^{2}$

Figure 6 shows the fluorescence intensity profile for the papers surface sized with starch solutions containing low viscosity cationic PAM and SA as additives. The addition of cationic PAM to oxidized starch solution made the starch solution remain on paper surface rather than penetrating into paper structure. The use of SA further decreased starch penetration. The change of starch distribution agrees well with the improved bending stiffness of the paper by cationic PAM and SA (Table 2). 


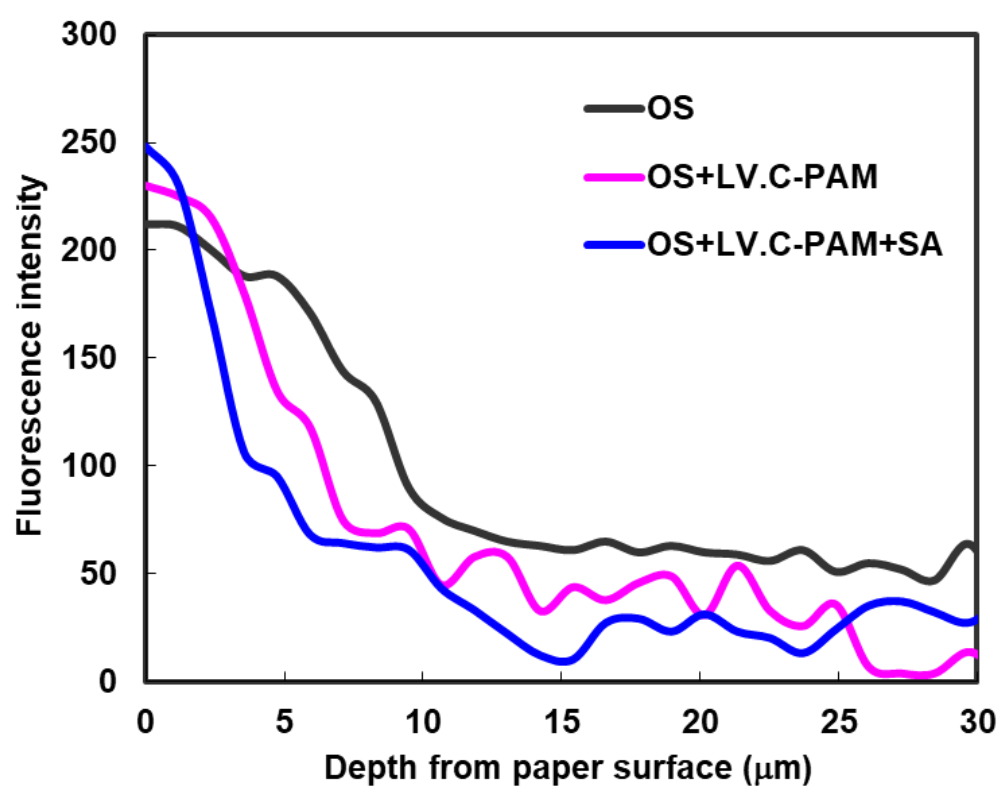

Fig. 6. Effects of addition of cationic PAM and SA on the penetration of starch solution into paper determined from the fluorescence intensity of acridine orange

\section{CONCLUSIONS}

1. This study was focused on the use of cationic PAM as a surface sizing additive to improve the surface sizing properties of paper. The effect of various cationic PAMs as surface sizing additives for improving starch holdout and bending stiffness was investigated.

2. Penetration phenomena of the surface sizing agents into paper and the enthalpy changes accompanying the mixing of cationic PAMs with oxidized starch have been investigated using confocal laser scanning micrometry (CLSM) and an ultra-sensitive thermal titration method, respectively.

3. The cationic PAM surface sizing additive improved bending stiffness and brightness, while anionic PAM did not show any effect. This supports the finding that cationic sites of c-PAM increased starch holdout on paper surface because of the electrostatic interaction with negatively charged fiber surface.

4. The viscosity and charge density of PAM were found to be important factors in surface sizing. Low viscosity PAM was more effective in improving the bending stiffness. High charge density PAM gave greater increase of bending stiffness than low charge density PAM probably because it increased the starch holdout.

5. The combined use of cationic PAM and SA further increased the bending stiffness, but the use of SA alone with anionic PAM showed a negative effect on bending stiffness.

6. The sequence of addition of PAM and SA was found to have great influence to the viscosity of starch solution. The addition of SA prior to high viscosity PAM caused a dramatic increase of viscosity indicating the strong electrostatic interaction between these two polyelectrolytes.

7. The penetration of starch solution was examined with CLSM, and it was shown that 
the addition of cationic PAM to oxidized starch solution increased the holdout of starch.

8. The enthalpy changes accompanying the mixing of cationic PAMs with oxidized starch was used to determine the molecular level interaction between PAM and starch in mixing. Low viscosity PAM showed greater enthalpy change in mixing with oxidized starch than high viscosity PAM, indicating that much stronger interaction between low viscosity PAM and oxidized starch.

\section{ACKNOWLEDGMENTS}

This work was supported by the Program in the Development of Clean Production Technology funded by the Ministry of Commerce, Industry and Energy, Korea (Grant No. 2003-A309-02).

\section{REFERENCES CITED}

Bown, R. (1998). "Particle size, shape and structure of paper fillers and their effect on paper properties," Paper Technol. 39, 44-48.

Chauhan, V. S., Bhardwaj, N. K., and Chakrabarti Swapan, K. (2011). "Inorganic fillermodification and retention during papermaking: A review," J. Indian Pulp Paper Tech. Asso. 23(2), 93-100.

Fairchild, G. (1985). “Coflocculation of fines and filler particles," Paperi ja Puu 11, 649653.

Gaudreault, R., Van de Ven, T., G., M., and Whitehead, M. A. (2005). "Mechanisms of flocculation with poly(ethylene oxide) and novel cofactors," Colloids and Surfaces A:Physicochem Eng. Aspects 268, 1-3, 131-146. DOI: 10.1016/j.colsurfa.2005.04.044

Gill, R. A., and Hagemeyer, R. W. (1992). "Fillers for paper," in: Pulp and Paper Manufacture, Vol. 6: Stock Preparation, R. W. Hagemeyer and D. W. Manson (eds.), TAPPI, Atlanta, GA, USA, pp. 19-38.

Hodgson, K. T. (1994). "A review of paper sizing using alkyl ketene dimer versus alkenyl succinic anhydride," Appita Journal 5(47), 402-406.

Hubbe, M. A., and Gill, R. A. (2016). "Fillers for papermaking: A review of their properties, usage practices, and their mechanistic role," BioResources 11(1), 28862963. DOI: 10.15376/biores.11.1.2886-2963

Im, W., Seo, D., Oh, K., Jeong, Y. B., Youn, H. J., and Lee, H. L. (2015). "Effect of preflocculated filler flocs and nano-sized coating binder on fold cracking of coated paper," J. Korea TAAPI 47(5), 91-97. DOI: 10.7584/ktappi.2015.47.5.091

ISO 5628 (2019). "Paper and board - Determination of bending stiffness- General principles for two-point, three-point and four-point methods," International Organization for Standardization, Geneva, Switzerland.

Jun, D. G., and Lee, H. L. (2008). "Effect of surface sizing with cationic polymer additives on the coating structure and coated paper properties," J. KTAPPI 40(1), 1-8.

Kajanto, I., (1998). "Structural mechanics of paper and board," in: Paper Physics, K. Niskanen (ed.), Fapet Oy, Helsinki, Finland, 193-221.

Kearney, R. L. (2005). "Starch," in: The Sizing of Paper, ( $3^{\text {rd }}$ Ed.), J. M. Gess and J. M. Rodriguez (eds.), TAPPI, Atlanta, USA, pp. 237-248. 
Kettuner, K., Ake, K., and Norell, M. (2000). "Process for the production of paper," U.S. Patent No. 6113741.

Kim, C. H., Rajabi Abhari, A., Jeong, Y. B., Youn, H. J., Kim, Y. S., and Lee, H. L. (2017). "Dextrin-poly(acrylic acid) copolymer as an additive for surface sizing with oxidized starch (I) - Effect on strength and drying rate," J. KTAPPI 49(2), 5-12. DOI: 10.7584/JKTAPPI.2017.04.49.2.5

Kolger, W., Spielmann, D., and Huggenber, L. (1992). "Cationic coating colors present state and outlook," in: TAPPI Coating Conf. Proc. Orlando, FL, USA, pp. 313-324.

Kumar, P., Negi, Y. S., and Singh, S. P. (2011). "Filler loading in the lumen or/and cell wall of fibers - A literature review," BioResources 6(3), 3526-3546. DOI:

10.15376/biores.6.3.3526-3546

Lee, H. L, Shin, J. Y., Koh, C. H., Ryu, H., Lee, D. J., and Sohn, C. M. (2002). "Surface sizing with cationic starch; Its effect on paper quality and papermaking process," Tappi J. 1(1), 34-40.

Lee, K. H., and Lee, H. L. (2006). "Preflocculation of GCC with cationic PAM and cationic starch and the influence of their dosage and shear rate on prefloc size," $J$. KTAPPI 38(4), 1-9.

Lipponen, J., Grön, J., Bruun, S. E., and Laine, T. (2004). "Surface sizing with starch solutions at solids contents up to 18\%," J. Pulp Paper Sci. 30(3), 82-90.

Lipponen, J., Lappalainen, T., Astola, J., Grön, J. (2004). "Novel method in quantitative determination of the starch z-directional distribution in cross sectional images of surface sized paper samples.” Nordic Pulp Paper Research J. 19(3), 300-308 (2004).

Ni, S., Wang, C., Jiao, L., Yu, Z., Wang, X., Jiang, S., and Dai, H. (2017). "Preparation of strong and stiff papers through surface sizing with starch and APMS," Appita J. 70(4), 386-393.

Nyström, R., Hedström, G., Gustafsson, J., and Rosenholm, R, B. (2004). "Mixtures of cationic starch and anionic polyacrylate used for flocculation of calcium carbonateinfluence of electron," Colloids and surfaces A:Physicochem. Eng. Aspects 234(1-3), 85-93. DOI: 10.1016/j.colsurfa.2003.12.012

Porubská, J., Alince, B., and van de Ven, T. G. M. (2002). "Homo- and heteroflocculation of papermaking fines and fillers," Colloids Surf. A 210(2-3), 223230. DOI: 10.1016/S0927-7757(02)00370-9.

Rajabi Abhari, A., Kim, C. H., Jeong, Y. B., Youn, H. J., Kim, Y. S., and Lee, H. L. (2017). "Dextrin-poly(acrylic acid) copolymer as an additive for surface sizing with oxidized starch (II) - Effect on strength and drying rate," J. KTAPPI 49(2), 13-22. DOI: 10.7584/JKTAPPI.2017.04.49.2.13

Samyn, P., Deconinck, M., Schoukens, G., Stanssens, D., Vonck, L., and Van Abbeele, H. (2010). "Modifications of paper and paperboard surfaces with a nanostructured polymer coating," Progress in Organic Coatings 69(4), 442-454. DOI:

10.1016/j.porgcoat.2010.08.008

Seo, D., Im, W.H., Youn, H. J., and Lee, H. L. (2012). “The effects of process variables for GCC preflocculation on floc and handsheet properties," Nordic Pulp Paper Res. J. 27(2), 382-387. DOI: 10.3183/npprj-2012-27-02-p382-387

Shirazi, M., Garnier, E. G., van de Ven, T. G. M. (2004). "Starch penetration into paper in a size press," J. Dispersion Sci. Tech. 25(4), 457-468.

TAPPI T205 sp-02 (2002). "Forming handsheets for physical tests of pulp," TAPPI Press, Atlanta, GA. 
Tommey, T., Pruszynski, P. E., Armstrong, J. R., and Hurley, R. (1997) "Controlling filler retention in mechanical grades," in: Preprint $83^{\text {rd }}$ Annual Meeting. Montreal, Canada, pp. B367-B372.

Weber, A., Herold, M., Brunner, H., and Tovar, G. E. M. (2004). "Bioconjugative polymer nanosphere studied by isothermal titration calorimetry," Thermochimica Acta. 415(1-2), 69-74. DOI: 10.1016/j.tca.2003.09.013

Article submitted: April 22, 2020; Peer review completed: May 16, 2020; Revised version received and accepted: May 22, 2020; Published: May 29, 2020.

DOI: 10.15376/biores.15.3.5489-5502 